SEÇÃO EXTRA

ENTREVISTA

\title{
ENTREVISTA COM ALBERTO ACOSTA, EM HOMENAGEM AOS 10 ANOS DA CONSTITUIÇÃO EQUATORIANA DE MONTE CRISTI
}

Entrevista:

Lilian Balmant

Emerique e Ilana Aló Cardoso Ribeiro

Tradução: Julia García Távora Menegaz

Tradução e revisão: Ilana Aló Cardoso

Ribeiro

Alberto Acosta
é economista, ex-
ministro, ex-presidente da
Assembleia Constituinte
do Equador, candidato à
Presidência e escritor. Essa
entrevista foi conduzida por
Ilana Aló e Lilian Emerique
em Quito, Equador, em 18
de outubro de 2018.

Nesta entrevista, Alberto Acosta fala sobre a sua atuação no processo constituinte do Equador; suas percepções sobre a Carta de 2008, considerando sua vocação participativa e eficácia constitucional; o papel das cortes constitucionais; e, ao final, apresenta um balanço do constitucionalismo equatoriano e um panorama sobre a ascensão do populismo de direita no mundo.

\section{P.1: "Você foi um dos principais articuladores nos processos consti-} tuintes, que terminou com constituição do Equador em 2008. Queria saber se pode nos indicar como esse processo começou e qual foi seu papel na articulação constituinte?"

R.1: Vou começar dizendo que o Equador tem uma longa, longa e muito complexa vida constitucional. Equador surge como república independente em 1830 e temos, até a atualidade, 21 Constituições. Então, os debates constituintes marcam definitivamente muitas épocas da vida do Equador e, na última etapa, tivemos um processo de debate constituinte muito intenso que começa sobretudo com o novo levantamento indígena. Isso se dá por maio, junho do ano de 1990. O levantamento indígena sintetiza uma longa luta, mas so- 
bretudo cristaliza um passo de objetos a sujeitos por parte dos indígenas. Então, emergem na vida política nacional como atores, mas além disso, como portadores de suas próprias visões de mundo. Eu anotaria isso como um ponto de partida. Muita história foi repetida, mas há uma emergência especial que se cristaliza justamente nessa data. Logo vem a Constituição de 1998, Constituição de 97, 98, eu mesmo estive envolvido como candidato na assembleia constituinte por parte do movimento indígena, por parte do Pachakutik. Não entrei, não tive os votos suficientes. Então, já havia uma reivindicação, um pleito que tinha como um de seus elementos básicos, como já havia dito, o mundo indígena, mas também levou desde outros setores de outros âmbitos, isso permite avançar a partir do ano de 2005, uma nova fase de reivindicação constituinte e isso abriu uma porta à um processo constituinte, eu estive desde o princípio e, posteriormente, seria constituinte igualmente presidente da Assembleia Constituinte no ano de 2007/2008.

\section{P.2: E quais foram as conquistas mais importantes deste documen- to, da carta de 2008 ?}

R.2: Bom, a primeira coisa que eu diria é que o mesmo processo constituinte. A diferença dos outros processos constituintes é nós vimos que no ano de 2007, 2008 foi muito participativo. Se abriu a porta para uma enorme possibilidade de discussão com amplos segmentos da sociedade desde a primeira vez que houve uma Assembleia Constituinte, que nós tivemos algumas, se convoca o povo para que se expresse a favor ou contra a Constituição. Também, foi feito um enorme esforço para que a sociedade continue diretamente nas relações dos textos. A constituição de 1998 foi escrita na cadeia de guerra do exército em uma cidade perto de Quito, na academia de Guerra, cidade de Montecristi. É uma Constituição aquartelada. Abrimos a porta para que se intervenha a sociedade e havíamos confirmado dez mesas constituintes por temas e essas mesas percorriam o país. Então, em primeiro ponto que destacaria é esse: a participação. Eu posso contar uma anedota, algo que foi repetido em outras ocasiões: eu era metade do tempo constituinte, e metade do tempo recepcionista porque estava recebendo o povo. Um processo muito rico, muito enriquecedor. Mais de 150 mil pessoas, muito mais. 300 mil, 300 em Montecristi. Milhares de propostas, 
Outro ponto claro que eu resgataria é que tudo o que tem que viver, tem de viver com o bem viver. Em ambos aspectos está a presença do mundo indígena. Muito forte, muito muito forte. Então, resgata-se o terceiro elemento fundamental, é tudo o que tem que ver com a plurinacionalidade, além do mundo indígena. artigos, constituições inteiras, milhares de ideias e de referências... um grande debate! Ponto um que eu resgato.

O ponto dois que resgato foi um verdadeiro momento de criação. Nos distanciamos pelas visões constitucionais tradicionais, conservadoras, que de alguma maneira estavam replicadas sempre nas 20 constituições anteriores, inclusive na divisões de funções de Montesquieu, as três funções executivas, legislativas, judiciais, nós ampliamos com outras duas. Há conflitos, sem dúvidas, há dificuldades nas partes que opero, se abria a porta em um momento de criação. Então, eu entraria para a apontar alguns aspectos chaves desta Constituição, na constituição incorpora o neoconstitucionalismo transformador, que não é só um marco jurídico para domar as relações existentes agora, como também um marco jurídico político para transformar essas relações. Não é uma constituição estática, para manter status quo, senão seria uma redundância. Não é simplesmente um marco jurídico, é um marco jurídico mais político de todos, é o documento político mais jurídico de todos, por sua vez.

Mas, mais do que isso, a constituição de um projeto de vida em comum. Prefiguramos uma sociedade, uma sociedade de equidades, liberdades, de igualdade, de sustentabilidade em todos os sentidos, uma sociedade democrática tem que construir-se democraticamente. Então aparecem alguns aspectos pontuais. Um deles são os direitos da natureza - pela primeira vez a constituição garantiu os direitos à natureza. A natureza como sujeito de direitos, que supera a visão tradicional da justiça ambiental. Os direitos ambientais são para os seres humanos em particular e os direitos ecológicos são para todos os seres vivos, incluindo os seres humanos.

Outro ponto claro que eu resgataria é que tudo o que tem que viver, tem de viver com o bem viver. Em ambos aspectos está a presença do mundo indígena. Muito forte, muito muito forte. Então, resgata-se o terceiro elemento fundamental, é tudo o que tem que ver com a plurinacionalidade, além do mundo indígena.

Um quarto aspecto é o modo de ver, é claro, que aprofundaram e ampliaram os direitos coletivos, que já vieram há um tempo atrás. Há aspectos adicionais de quando se fala, por exemplo, da cidadania universal. A constituição recorre à muitíssimos elementos muito interessantes que constituem a base para construir outro tipo não 
só de sociedade adequada, mas também para pensar outro tipo de civilização, em termos mais globais.

P.3: E quais são, em sua opinião, os principais problemas de eficácia dos dispositivos constitucionais que se colocam passados $\mathbf{1 0}$ anos de vida desde a nova constituição?

R.3: Muitos, muitos. Por um lado, na primeira leitura pode ser frustrante. Pode ficar pouco satisfeito. Mas, por outro lado, começa a se dar conta de que a constituição teve um impacto muito mais potente do que podemos imaginar à primeira vista. No âmbito internacional, temas que surgem da Constituição do Equador são motivo de discussão cada vez mais forte (os direitos da natureza). Por que? Os direitos das natureza não surgem a partir do Equador, pessoas já trabalhavam os direitos da natureza antes, nós já sabíamos. Mas está se formando um grande movimento mundial pelos direitos da natureza, há muitas iniciativas, seria longo falar sobre isso.

Outro ponto importante é o bem viver. O bem viver é também motivo de discussão em muitíssimos países. No Brasil mesmo eu tenho um livro sobre o bem viver, que já tem várias edições. Esse livro foi difundido em outras partes do mundo, em vários idiomas. Na França, na Alemanha, Holanda, Espanha... Então, o que é importante no livro é ensinar que isso é uma questão que está sendo discutida, então, por aí, eu vejo como um elemento interessante. Por outro lado, apesar das frustrações que podemos ter, paulatinamente na sociedade equatoriana, há pessoas que começam a reclamar certos direitos de participação, os mesmos direitos à natureza, os direitos do bem viver, vemos que certos processos, incluso com sentenças jurídicas muito interessantes.

Mas, claro, se me permite, a constituição foi atropelada sistematicamente desde que nasceu. Foi aprovada em 20 de outubro, como eu disse. Vai completar dez anos no sábado, 20 de outubro de 2018. A constituição foi violado em seu primeiro dia, quase. Foi publicada em 20 de outubro, e em poucas horas, poucos dias, o tribunal constitucional da velha constituição, do velho regime, se metamorfoseia em corte constitucional de transição. Sim, sem nenhuma atenção. Em janeiro de 2009, já se viola a constituição com a Lei de Mineração, reconhecidas pela corte de constituição. Há sistemáticas violações à constituição. 
O presidente da república, de então, dizia que a constituição ia durar 300 anos, que é um canto na vida, a melhor constituição. Em alguns aspectos tornou-se uma camisa de força. Por exemplo: a justiça. Então ele literalmente disse que ia meter a mão na justiça e meteu a mão na justiça. Acabou com a possibilidade de uma justiça independente e autônoma.

No dia 15 de janeiro de 2013, disse textualmente que é um erro supor que os direitos humanos se subordinam aos supostos direitos à natureza, assim ele disse. Não entendeu, não entendeu e nunca Ihe interessou.

Além do mais, encheram de conteúdo o bem viver. O transformaram em um dispositivo de poder e uma ferramenta para forçar o desenvolvimento e um mecanismo de propaganda. Muitas coisas não se cumpriam: a participação cidadã foi atropelada, porque Correa a transformou em um caudilhismo do século 21 e terminou por controlar todas as funções do Estado.

P.4: E quais são as considerações mais importantes na interpretação da corte constitucional nas questões constitucionais? Quais são os erros e os acertos na corte?

R.4: Eu diria que a corte constitucional não cumpriu o papel que se esperava, que teria de proteger a constituição com certa urgência. Terminou sendo uma carta de ressonância da presidência da república, recebia ordens da presidência da república. Isso normalmente seria estranho, mas essa é uma história que explica de alguma maneira a recorrência de problemas constitucionais no Equador. Não houve nunca um espaço, uma entidade, uma organização encarregada de fazer respeitar a constituição. A constituição sempre foi se acomodando. O mesmo se sucedeu com a Constituição atual e isso é lamentável.

P.5: Então, a constituição de 2008, em sua opinião vai ser substituída por outra no Equador, ou pode sofrer alterações com esse novo governo de Lenin Moreno que substitui o de Rafael Correa?

R.5: Há gente que também está pleiteando uma nova assembleia constituinte. Inclusive até o Presidente Correia pleiteia uma nova assembleia constituinte. Ele que disse que a constituição vai durar 
300 anos, que é a melhor constituição do mundo, tudo o que eu já contei, e agora quer uma nova constituição e há muita gente que pleiteia uma nova constituição, parte dos problemas do Equador. Apesar da constituição ter sido respaldada pela maioria do povo e de haver um amplo debate constituinte.

P.6: Em sua avaliação, a constituição do Equador teria instrumentos suficientes para resistir as transições de governo em um contexto de hiperpresidencialismo?

\section{0 desafio é o} mesmo: como fazer que a cidadania, a sociedade assuma o debate e entenda que a constituição é uma caixa de ferramentas para a cidadania, não para os políticos.
P.6: Lamentavelmente, como já foi demonstrado, não foram suficientes. O tema de hiperpresidencialismo e de presidencialismo é característico em todas as constituições equatorianas e da América Latina. São presidencialistas. O problema é como vamos resolver essa questão, como vamos resolver, qual é uma saída. Inclusive na própria constituição há certos elementos que favorecem o presidencialismo, mas Correia em seu caminho se utilizou para transforma-los em um caudilho do século XXI, sinteticamente um atropelo a constituição.

P.7: Já nos encaminhando para o fim da entrevista, gostaríamos de saber quais são os principais desafios para essa etapa do constitucionalismo no Equador?

P.7: O desafio é o mesmo: como fazer que a cidadania, a sociedade assuma o debate e entenda que a constituição é uma caixa de ferramentas para a cidadania, não para os políticos. O governo, as Assembleias, a Assembleia Nacional, a justiça não é só para os juízes e juízas, os advogados e advogadas, é para todos os cidadãos que tem que assumir a constituição como uma caixa de ferramentas. Digo que no bolso de cada pessoa deve haver sempre uma constituição

\section{P.8: O projeto constituinte no Equador está em perigo?}

R.8: Bom, o grande problema é que, em primeiro lugar não se quis colocar em marcha a plenitude da constituição. O bem viver não é uma alternativa de desenvolvimento. $O$ bem viver é uma alternativa ao desenvolvimento. Se tivéssemos colocado esse conjunto em prática, entrava com força tudo que diz respeito a mãe terra, os direitos 
da natureza, não podíamos seguir ampliando o extrativismo. Correia ampliou o extrativismo petroleiro, o extrativismo mineiro, pela primeira vez tivemos mineração no Equador. Tivemos também uma ampliação dos extrativismos agroexportadores, então tudo foi-se debilitando e levando a não colocarmos em prática a constituição.

Todos os países vão tirar máximo proveito da natureza porque os preços das matérias-primas são altos e nos esquecemos de processos de transformação da matriz produtiva. Estamos vivendo no caso equatoriano, mas estou falando e pensando no Brasil, falando e pensando na Bolívia, estou falando e pensando na Argentina.

E nessa etapa com preços altos, se renuncia a pobreza, mas os ricos ficam mais ricos porque não se afetam com a modalidade de acumulação de capital. Os grandes ricos econômicos do Equador, os tradicionais, os oligárquicos e os novos, fazem muitos negócios como nunca na história. Então, é o que eu chamo do ciclo da lagarta. Mesmo que se diminua a pobreza, sempre se aumenta mais a concentração da riqueza porque é muito dinheiro para processar.

\section{P.9: E que expectativas você tem com esse projeto atual de transi- ções democráticas a direita?}

R.9: Bom, o problema é que os modernos progressista, seja o governo do Brasil, seja o governo de Argentina, governo do Equador, incluindo o governo do Evo Morales, seja o governo Venezuela nunca aceitaram a lógica de acumulação de capital. Ou melhor dizendo possibilitaram que se reduza a pobreza, mas como possibilitaram? Através de práticas e políticas de subsídio paternalistas e isso não gerou uma apropriação das pessoas a partir dos direitos.

Eu estive em São Paulo em junho de 2013 e durante toda a semana que começaram os protestos e as pessoas estavam nas ruas se manifestando. Grande parte daqueles manifestantes e grupos sociais eram os que deixaram de ser pobres com o PT e que queriam consumo, mais consumismo, porque queriam uma maior participação e não um governo tão autoritário e ríspido, eram os que queriam um maior combate à corrupção que estavam presente.

Estava aí a explicação: o que acontece é que o PT e os outros governantes progressistas - não de esquerda - não entenderam realmente 
Pessoalmente, não sou

partidário para sair acreditando que os problemas se resolvem a partir do Estado. $O$ mercado definitivamente não, não é o caminho, mas tampouco é o Estado. Temos que repensar a sociedade partindo do comunitário, com muita participação desde as massas, então lideranças mais horizontais, mais compartilhadas, lideranças que permitam inclusive as alternâncias democráticas permanentes. o que estava passando e isso foi gerando umas condições perversas que estão sendo aproveitadas pelos grupos da extrema-direita até de recorte fascista. Mas o caso do Equador também é o caso do Brasil.

Com os governos progressistas de PT e o governo do Correa houve retorno ao neoliberalismo. Não a políticas neoliberais. Correia abriu o Equador ao capital internacional em 2014. Correia articulou a flexibilização no ano de 2016. Correia firmou um tratado de livre comércio com a União Europeia em 2016. Abriu a porta das privatizações, além disso realizou concessões de 50 anos a grupos transnacionais vinculados a grupos oligárquicos dos quatro maiores portos do país sem licitações.

Todas aquelas ações que criavam as condições para que os grupos de direita, os grupos econômicos poderosos que se beneficiaram com o governo de Correia, pudessem exigir vez mais.

P.10: Tendo em vista toda essa problemática, que tipo de lideranças políticas necessitamos para conter esse avanço predatório sobre a constituição?

P.10: Maior participação das pessoas a partir do comunitário. Pessoalmente, não sou partidário para sair acreditando que os problemas se resolvem a partir do Estado. O mercado definitivamente não, não é o caminho, mas tampouco é o Estado. Temos que repensar a sociedade partindo do comunitário, com muita participação desde as massas, então lideranças mais horizontais, mais compartilhadas, lideranças que permitam inclusive as alternâncias democráticas permanentes. 